\title{
Juan Carlos Barroso (1925-1995): un testimonio de la renovación artística de postguerra
}

\section{Juan Carlos Barroso (1925-1995): a case of artistic renovation in the Post-war period}

\author{
Sonia D’ Agosto Forteza \\ Universidad de Sevilla (España) \\ sdagosto@us.es \\ Fecha de recepción: 14/12/2018 \\ Fecha de aceptación: 24/07/2019
}

\begin{abstract}
Resumen
En las primeras décadas de la Postguerra española muchos artistas de capitales de provincia intentaron renovar sus propios ambientes culturales. Algunos de ellos fueron artistas menores que el tiempo ha olvidado, como es el caso del pintor jerezano, Juan Carlos Barroso Jiménez. En este artículo vamos a rescatar su trayectoria vital y artística a través del estudio de sus obras, con la intención de introducirnos en los distintos lenguajes estéticos que empleó, entre ellos, las interpretaciones del clasicismo pictórico, el cubismo de corte cezaniano heredado de Vázquez Díaz y el fauvismo transmitido por los pintores de la Segunda Escuela de Vallecas.
\end{abstract}

Palabras clave: Pintura sevillana; Arte español durante el franquismo; Grupo 49; Juan Carlos Barroso (1925-1995); Daniel Vázquez Díaz (1882-1969); Segunda Escuela de Vallecas.

\begin{abstract}
In the first decades of the Spanish Postwar period, many artists from provincial towns tried to restart their cultural environments. Some of them were minor artists that time had forgotten, as is the case of the painter from Jerez, Juan Carlos Barroso Jiménez. In this article we will try to rescue his personal and artistic trajectory by studying his works, with the intention of learning the different aesthetic languages that he used. Among them, the interpretations of pictorial classicism, the Cezanian cubism inherited from Vázquez Díaz and the fauvism inherited from by the painters of the Second School of Vallecas.
\end{abstract}

Keywords: Seville Painting; Spanish Civil Post-war period; Grupo 49; Juan Carlos Barroso (1925-1995); Daniel Vázquez Díaz (1882-1969), Second School of Vallecas. 


\section{INTRODUCGIÓN}

Para comprender la producción artística de pintores como el que nos ocupa en este artículo, es imprescindible tener en cuenta el espacio histórico donde se encuadra, pues no eran tiempos fáciles para un arte libre sin restricciones. De lo que no cabe duda es que la producción artística de esta etapa histórica es un fiel reflejo del periodo cultural que le tocó vivir.

Una vez dicho esto, es importante tener en cuenta que, finalizada la Segunda Guerra Mundial, comenzó una campaña de los países Aliados para aislar a España. Al finalizar los años cuarenta, el régimen de Franco estaba muy interesado en dar una visión de apertura al exterior para evitar el boicot económico internacional. La situación cambió a partir de la firma de unos acuerdos con los Estados Unidos de América en el año 1953. Desde esta fecha, podríamos afirmar que comenzó a producirse una tímida recuperación de la economía española, que se manifestó principalmente en el sector turístico.

Es en este este momento, cuando el régimen franquista comenzará a aprovechar el arte para demostrar su nuevo talante aperturista. Lo hará, controlando, eso sí, todas las manifestaciones culturales que se produzcan. Según el historiador Cabañas Bravo (Cabañas, 1996, p. 87), la década de los años cincuenta abre un nuevo periodo artístico que podría dividirse en dos etapas claramente diferenciadas:

La primera, abarcaría el periodo que comprende la dirección Joaquín RuizGiménez, ocupando la cartera de Educación Nacional, desde el cambio de gobierno en 1951, hasta su dimisión en 1956, por los conflictos universitarios (Tamames,1989, pp. 423-424). Bajo su mandato se iniciaba una fase aperturista paralela a la ya iniciada por el Ministerio de Asuntos Exteriores. Este periodo se caracterizó por el planteamiento y debate de la problemática figuración/abstracción o arte representativo/arte no figurativo.

La segunda, comprendería desde el año 1957 hasta 1962, coincidiendo con el final del Quinto Gobierno del Régimen o Gobierno de la Estabilización de los primeros llamados tecnócratas del Opus Dei.

Asimismo, se creó el Instituto de Cultura Hispánica en abril de 1947, en el seno del Ministerio de Asuntos Exteriores, aprobándose su Reglamento Orgánico por Decreto de 18-4-1947. Esta institución iba a estar encabezaba por Alberto Martín Artajo (1945-1957), y dirigida por Alfredo Sánchez Bella (1948-1956), hombre que supo aprovechar con acierto sus dotes diplomáticas para apropiarse del arte que más convenía a las nuevas políticas del Estado. Así pues, los artistas empezaron a promocionarse a través de plataformas que el gobierno autorizaba y controlaba, en forma de Salones o Bienales.

Eugenio d'Ors (1881-1954), fue figura clave de la renovación pictórica y magnífico crítico de arte. Desarrolló una gran labor en la promoción de las artes 


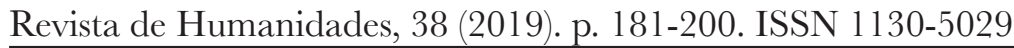

a través de la creación de la Academia Breve de Crítica de Arte, del Salón de los Once y sus Exposiciones Antológicas. A partir de su fundación, los miembros de la Academia celebrarían todos los años una muestra de once autores. Cada uno de ellos iba a ser presentado por uno de los académicos, razón por la que aquellos certámenes pasarían a denominarse: "Salón de los Once" (Sánchez, 1963, p. 22).

Por otra parte, fue de capital importancia para la proyección internacional del arte español, la celebración de las tres Bienales Hispanoamericanas de Arte. La primera se celebró en Madrid, en 151, bajo los auspicios del Instituto de Cultura Hispánica y el ministro de Educación Nacional, Joaquín Ruiz Giménez. La segunda en 1953, en La Habana (Cuba) y la tercera en 1955, en Barcelona. Hay que decir que estos certámenes, no estuvieron exentos de polémica. Artistas extranjeros y exiliados como Picasso (Picasso et al., 1951), denunciaban indignados la situación en un manifiesto dirigido al régimen político convocante.

En este contexto, es importante tener en cuenta que muchos de los artistas que se quedaron en el país, también tuvieron que atravesar su propio exilio interior (Gómez, 2009, p. 117). Ellos no tuvieron que cruzar ninguna frontera para sentirse extraños en su propia tierra. Muchos tuvieron que sostener y digerir sentimientos como el desarraigo existencialista, la angustia vital o el vacío.

Las Bienales Hispanoamericanas de Arte y, por otro lado, los Salones patrocinados por Eugenio d'Ors, desde sus orígenes habían fomentado el apoyo a un arte antiacadémico. A partir de 1949, se incorporarían algunos de los principales protagonistas de la vanguardia más radical de los años cincuenta: Tàpies, Cuixart, Oteiza, Saura y Millares. De la misma manera que la renovación artística de finales de los años 40 y 50 vino de la mano de grupos como Dau al Set (1948), el Grupo Pórtico en Zaragoza (1947) o el Movimiento Indaliano en Almería (1946), podemos aseverar, que algo semejante ocurrió en Sevilla con la aparición del Grupo 49 y la Joven Escuela Sevillana.

En Andalucía la modernidad y la vanguardia no existían antes de la Guerra Civil, si acaso, afirma Fernando Martín (Martín, 1992), se las podía rastrear a través de algunas revistas literarias de vuelos ultraístas y surrealistas como Grecia o Mediodía editadas en Sevilla, o la revista Litoral, editada en Málaga; también contribuyó el acto parasurreal Telefonía Celeste protagonizado por el escritor Adriano del Valle y el pintor José Caballero en el Ateneo de Sevilla 12 de enero de 1935, así como la influencia neocubista, de clara afiliación cezaniana del pintor onubense Vázquez Díaz, que regresó a España en 1918, después de permanecer en París durante catorce años.

Esta especie de protovanguardia ocurrida entre los años 1919 y 1935 (Burgos, 2007 , p. 5), confirma que la vanguardia literaria en Andalucía se produjo y estaba dispuesta a abrir brecha en la renovación pictórica, pero la Sevilla tradicional no aceptaba el ultraísmo, ni el surrealismo, y aunque hubo artistas importantes de vanguardia, como Pablo Sebastián, habría que esperar a que, desde instancias 
oficiales, se permitiera cierta apertura, como empezó a ocurrir en el Club La Rábida, a partir de 1949.

El Club La Rábida tenía su sede en los sótanos de la Escuela de Estudios Hispanoamericanos, concretamente en la calle Alfonso XII. Allí se daban cita músicos, poetas, escritores, pintores, etc. La cultura hispalense tenía por fin un lugar donde expandirse, oportunidad que no perderían los jóvenes recién licenciados por la Escuela Superior de Bellas Artes de Santa Isabel de Hungría. Gracias a los concursos que se celebraban en el Club La Rábida, se estimuló gradualmente la renovación plástica. Los artistas se sentían motivados en un espacio donde se les permitía crear y exponer con libertad, además de compartir experiencias comunes. Alejados de las rigideces de ciertas doctrinas de la Academia de Bellas Artes, encontrarían un lugar donde podían exponer sus obras sin ser censurados.

Por otro lado, para entender el ambiente artístico sevillano es importante tener en cuenta que el pintor Vázquez Díaz instauró la Beca de Paisaje en La Rábida (Huelva), a la que tuvieron acceso muchos alumnos de la Escuela de Santa Isabel de Hungría, donde pudieron asimilar gran parte de su corpus teórico. No hay que olvidar que, además fue el profesor de gran parte de los artistas que constituyeron la Segunda Escuela de Vallecas, fusionándose así, los conocimientos adquiridos de las vanguardias parisinas con la tradición artística local. Igualmente, Benjamín Palencia (1894-1980) fue el promotor principal de esta última escuela y el portador de la corriente fauvista. Este pintor se convirtió en el gran descubrimiento de los jóvenes artistas sevillanos que asistieron a la Primera Bienal Hispanoamericana de Arte en Madrid.

Una de las primeras muestras que iban a anunciar un cambio estético en la ciudad hispalense, fue la exposición de El Grupo 49. La exhibición se celebró en el Club La Rábida (D’Agosto, 2014, p. 43-45), el mes de abril del año 1952, gracias a la iniciativa de los pintores Antonio Milla y Ricardo Comas, alumnos recién egresados por la Escuela Superior de Bellas Artes de Santa Isabel de Hungría de Sevilla (Vid. Exposición Grupo 49, 1952; Olmedo, 1951a, p. 158; Hispaleto, 1952, p. 6; Olmedo, 1952, p. 18; Torres, 1976, p. 30).

Si bien, aquella agrupación realizó una sola exposición como Grupo 49, aquella iniciativa resultó ser una propuesta con una larga proyección posterior que daría como fruto el deseado cambio de los lenguajes artísticos.

Esta agrupación supuso un primer paso para la apertura estética y abrió nuevos recorridos artísticos a través de la fundación de la futura Joven Escuela Sevillana. Sus componentes que ostentaban la segunda generación de pintores surgidos de la Escuela Superior de Bellas Artes, iniciarían una etapa de renovación en el panorama pictórico sevillano de los años cincuenta, a través del tratamiento novedoso de su pintura. En el contexto de mediados del siglo XX, su obra significó el nacimiento de un arte más alternativo donde se ponían en cuestión los presupuestos estéticos de 


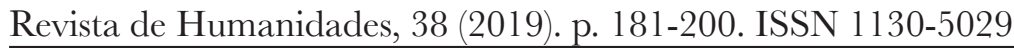

cuño académico. El Grupo 49 y posteriormente la Joven Escuela Sevillana, iban a abarcar prácticamente toda la década de los años cincuenta, amparados por el Club La Rábida y el Ateneo Hispalense (Sánchez, 2009, p. 128), instituciones que iban a jugar un papel decisivo en la configuración de un nuevo arte que culminaría en los años sesenta.

La trayectoria artística del pintor Barroso, que vamos a analizar a continuación, se desarrolla en este complejo contexto histórico y cultural, al que hay que añadir una idiosincrasia local fuertemente arraigada. Baste decir que el escultor Antonio Cano Correa (1909-2009), en su etapa de estancia en Sevilla, destacó por su modernidad con el controvertido grupo de Muchachas al sol (1962). El arquitecto Rodrigo Medina Benjumea, uno de los técnicos encargados del monumento, le dijo a Cano Correa: "Haga usted una cosa que produzca escándalo" ("Escándalo por las Muchachas", 2009). Y lo causó, pues la escultura se retiró de su emplazamiento original con el beneplácito de Romero Murube, que por aquel tiempo era el director conservador del Real Alcázar sevillano, y José Hernández Díaz, profesor de la Escuela Superior de Bellas Artes y futuro alcalde de Sevilla. El gusto de la ciudad todavía no estaba preparado.

Lo mismo ocurriría en la pintura cuando Luís Gordillo presentaba sus obras informalistas en la Sala de Información, a su vuelta de París, en el año 1959, muestra que acabó siendo clausurada.

\section{VOCACIÓN Y FORMACIÓN ARTÍSTICA}

Juan Carlos Barroso Jiménez nacía el 17 de diciembre de 1925 en Jerez de la Frontera; su padre y su tío regentaban una industria litográfica, oficio con el que tuvo contacto a temprana edad y que le confirió gran habilidad para los rudimentos del dibujo. Rápidamente aprendió a confeccionarse sus propios colores, elaborando tintas a partir de la maceración de hojas de plantas y flores, utilizándolas a modo de acuarelas. Su primera manifestación artística fueron cabezas, sortijas o muñecos articulados elaborados con barro cocido. En su búsqueda del sentido artístico de las cosas, tuvo una primera toma de contacto con el arte moderno al descubrir las ilustraciones de Freixas de la revista Lecturas, en los años 1933-1936. Se sintió atraído por el realismo y geometrismo de estas, asociando sus formas con un sentido nuevo del diseño. Sería una modernidad que se perdería con la iniciación de la Guerra Civil. (D. Fernández, comunicación personal, 17 de octubre de 2012).

En aquellos comienzos, la vocación del pequeño artista oscilaba entre la pintura y el modelado, sintiéndose atraído por el dibujo de nuevos diseños y litografías, así como del modelado y tallado en ladrillo. Siendo uno de sus primeros ensayos profesionales, el diseño autodidacta de etiquetas para colaborar en la industria litográfica que regentaba su familia. 
Comenzada la Guerra Civil, asistió a clases de modelado, sin tener edad suficiente para matricularse, con el escultor Juan Luís Vassallo Parodi (1908-1986), en la Escuela de Artes y Oficios de Jerez (Pérez, 2008, p. 143; Merino, 1987).

Al terminar el conflicto bélico, Barroso ya tenía catorce años y pudo asistir como alumno oficial en dibujo artístico, trabajando la técnica del carboncillo y el óleo, bajo la dirección del pintor Miguel Barrón, artista formado en Madrid y discípulo de Cecilio Plà, que enseñó al joven las técnicas para ejecutar una pintura "lamida", contrariando todo su estilo personal de dibujar composiciones de carácter geométrico de tintes cubistas. A partir de ahí, y en poco tiempo, pasaría a dominar la tinta grasa a base de jabón, las plumillas especiales y los buriles que exigía la técnica del grabado. En 1944, marchó a Sevilla para ingresar en la Escuela Superior de Bellas Artes de Santa Isabel de Hungría [1], instalándose en la Residencia Universitaria de los Salesianos hasta 1952, institución que potenció en el pintor un profundo sentimiento católico.

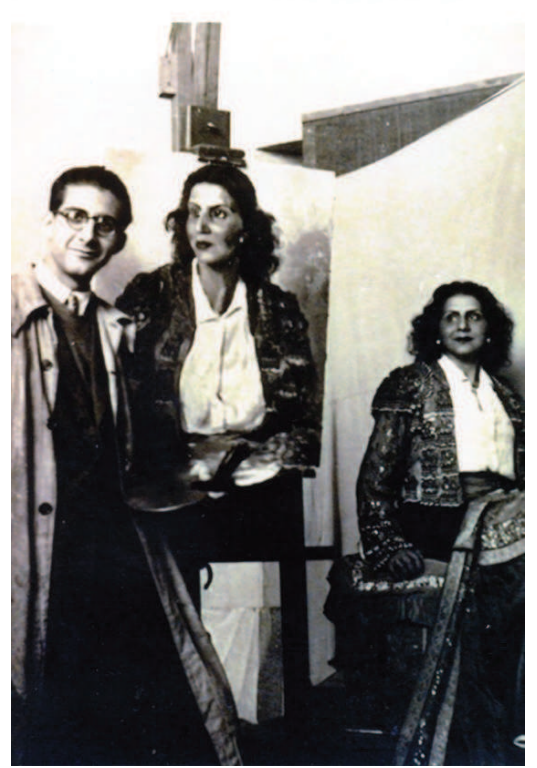

Figura 1. Barroso en las clases de pintura de la Real Academia de Bellas Artes de Santa Isabel de Hungría

Barroso rápidamente se percató del ambiente retrógrado conservado por los profesores de la escuela de Bellas Artes donde la nostalgia hacia el periodo Barroco era evidente. Estaban bien vistos los grandes maestros como Zurbarán, Velázquez y Goya, con los que, al parecer, se terminaba el arte válido para la enseñanza. El Impresionismo tenía cierta aprobación y se convirtió en la expresión plástica más 


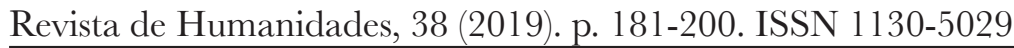

moderna admisible. Es un dato importante para entender el ambiente docente de la escuela, que Picasso estaba terminantemente prohibido, no se podía hablar de él y todo lo que rodease su producción artística.

Era evidente que el arte de provincias presentaba más dificultades a la hora de absorber las novedades que se producían en otros ambientes artísticos. Núcleos urbanos como Madrid o Barcelona, eran poseedores de escenarios culturales mucho más abiertos y desarrollados, que contrastaban con el retraso que se vivía en Sevilla. En el panorama artístico nacional no existió una clara solución de continuidad de las vanguardias artísticas de preguerra. Por otro lado, y sobre todo en los comedios de la década de los 50, había una discreta permisividad por parte de las instancias públicas en el desarrollo de un arte distinto y renovador, pero siempre bajo la atenta mirada de los poderes fácticos.

A la pintura sevillana le llegó la oportunidad de cambio en 1946, con el ingreso del profesor jienense Miguel Pérez Aguilera (Martínez, 1977, p. 37), en la Cátedra de Dibujo de la Escuela Superior de Bellas Artes de Santa Isabel de Hungría. Procedía del colectivo de pintores de la Escuela de Madrid, denominación que se atribuye a los críticos Ramón Faraldo (Faraldo, 1953) y Manuel Sánchez Camargo (Sánchez, 1954). Dicha escuela fue de algún modo, un camino fuera de las tendencias de la ideología franquista (Fernández, 2015, pp. 101-102). Sus integrantes se dieron a conocer por primera vez en la Galería Buchholz en 1945, en un certamen que se titularía "Joven Escuela Madrileña". Aguilera, gracias a su formación en París y posteriormente en Madrid, mostró una mentalidad abierta, actitud que chocó no pocas veces con el magisterio ya establecido en la escuela sevillana. Su presencia favoreció a los alumnos de la promoción de Barroso y a generaciones venideras, beneficiándolos con una formación más avanzada y actualizada. De lo que no cabe duda, es que sus enseñanzas fueron un pilar importante en la renovación de la plástica hispalense.

La etapa académica de Barroso, que abarcó desde 1944 hasta 1949[2], estuvo llena de nuevas oportunidades. Forjó muy buenas amistades con compañeros de la escuela y formó parte del Grupo 49. Dicha agrupación estaba compuesta por: Dolores Fernández, que con el tiempo se convertiría en su esposa, Ricardo Comas, Joaquín Ojeda, Antonio Milla, Francisco Reguera, José Duarte (Vid. Danvila,1990; Gauthier, 2006; Bonet, 2013; D’Agosto, 2017) y Antonio Rodríguez de Trujillo (Vid. D'Agosto, 2016).

En la muestra del Grupo 49, Barroso presentó cinco obras: Retrato, Autorretrato [3], Apunte (Córdoba), Apunte (Montoro) y Bodegón Filosófico [4], con el que obtendría la Beca Murillo poco después. Resulta asombroso que esta última obra hubiese obtenido dicho galardón, por el significado oculto que se desprende de su simbología. En el cuadro aparece representado un búho, que al igual que la lechuza, son atributos del sueño, de la muerte y de la noche. Le acompaña una vela, que en este caso está apagada y un libro que exhibe unas hojas en blanco. Según Revilla (1990), 

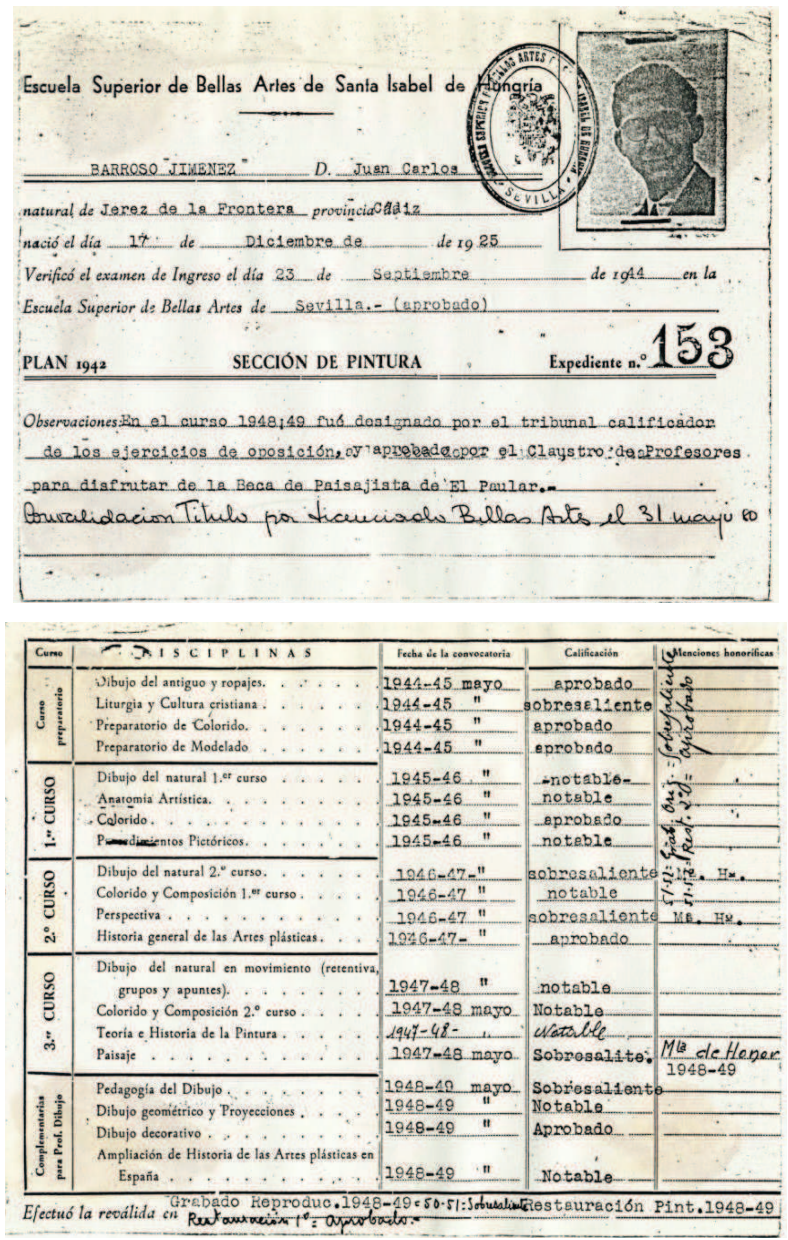

Figura 2. Calificaciones obtenidas por Juan Carlos Barroso en la Escuela Superior de Bellas Artes de Santa Isabel de Hungría

la vela tiene el poder iluminar en la oscuridad y mantiene una estrecha relación con la vida. El búho representa la tristeza, el abandono o la oscuridad y la lechuza viene a significar la cerrazón intelectual, la estupidez o la cortedad. Así pues, este bodegón lo que representa es una silenciosa y osada denuncia sobre el ambiente cultural que le tocó vivir al pintor. Para él, el conocimiento que le rodeaba era equivalente a un libro sin texto. No deja de sorprendernos que esta suerte de vanitas hubiese sido premiada por un tribunal supuestamente cualificado. Con obras como esta, podemos intuir que el artista era bastante consciente de la pobreza cultural que le rodeaba. Hombre de fe, muchas veces tuvo que aceptar el desencanto fomentado por un poder que no atendía a las necesidades espirituales de sus administrados y que, muy por el contrario, lo que hacía era reprimir y controlar su vocación creadora. El verdadero triunfo de Barroso fue que le premiasen esta obra. 
Al igual que el tribunal, tampoco la crítica cayó en estos detalles y se limitó a decir, "Barroso ha obtenido la Beca Murillo con un bodegón sobrio de color, rico de matices y ágilmente diseñado, con sentido de moderna estilización decorativa" (Olmedo, 1951b, p. 6).

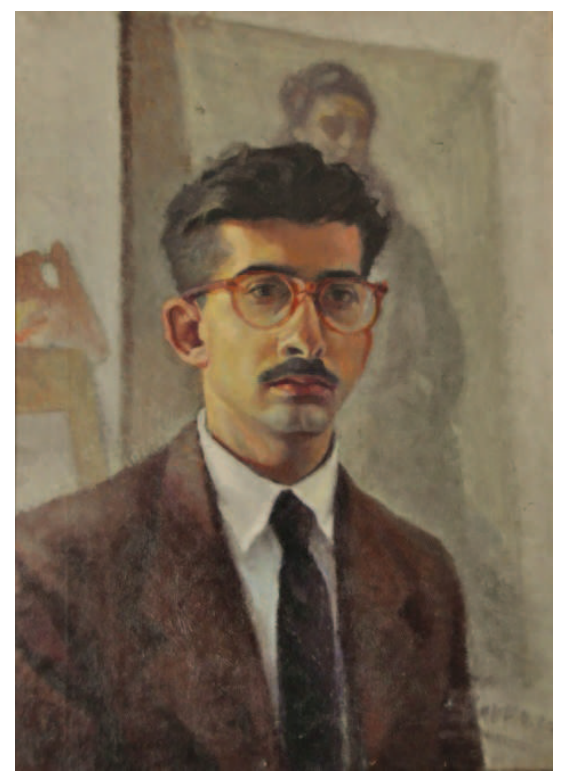

Figura 3. Juan Carlos Barroso, Autorretrato, 1948. Óleo sobre lienzo, $73 \times 53$ cm, Córdoba, Colección particular

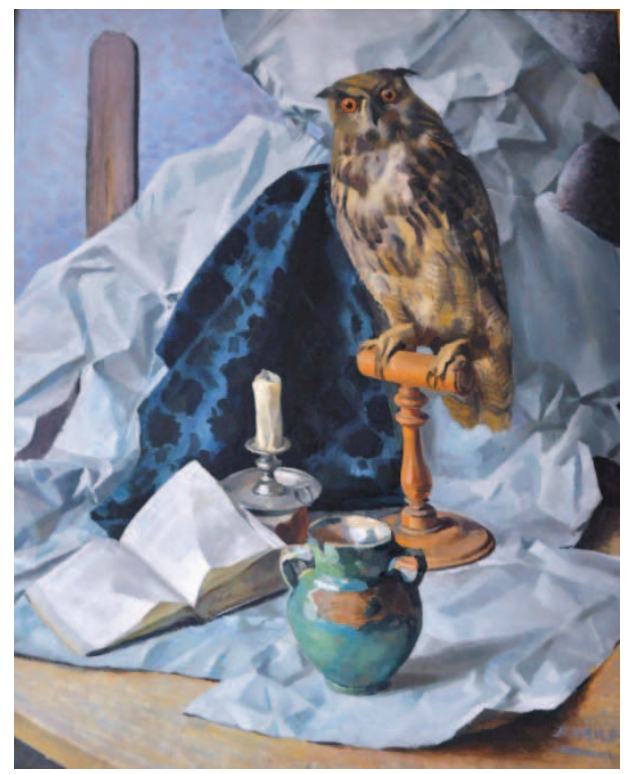

Figura 4.Juan Carlos Barroso, Bodegónfilosófico, 1951. Óleo sobre lienzo, 100x82 cm, Córdoba, Colección particular. Premio Murillo

Consciente de las posibilidades del lenguaje de la pintura, continuó trabajando con entusiasmo. Durante su carrera, se entregó por entero a la formación; participó en numerosas exposiciones colectivas; realizó exposiciones individuales de pintura en Sevilla, Madrid, Córdoba, Granada y Segovia; y asistió a la Exposición Nacional de Bellas Artes de 1946, con los mismos compañeros que formaban parte del Grupo 49.

Durante los veranos de 1947 y 1948, Barroso combinó los estudios universitarios con el cumplimiento del Servicio Militar, de modo que realizó la Milicia Universitaria del Ejército de Tierra en los campamentos de Montejaque. Allí participó en la ilustración de la revista Ejército, donde ensayó su dibujo haciendo multitud de bocetos sobre el paisaje que le rodeaba y el ambiente militar que le tocó vivir [5].

Asimismo, obtuvo un número considerable de becas de Paisaje como la de El Parador de San Francisco en Granada, en 1948 o la de El Paular en Segovia, en 1949 (Esteban, 1991, p. 167); en 1950 obtenía la beca para pintar en Santa María de La Rábida, participando en la posterior colectiva que se iba a llevar a cabo con la llegada del otoño. 


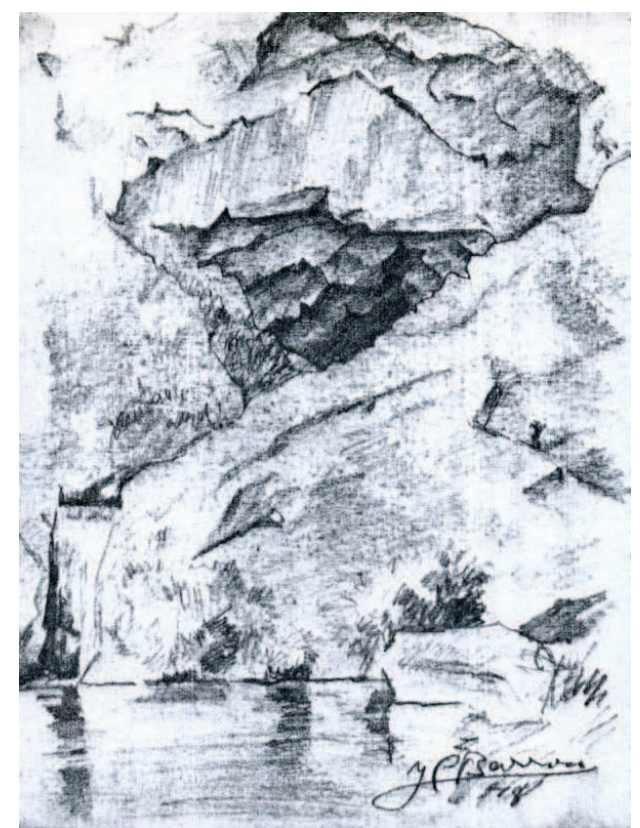

Figura 5. Juan Carlos Barroso, Cueva del Gato (Benaoján), 1948. Lápiz sobre papel, 17,5x13 cm, Córdoba, Colección particular

Así describía Olmedo los trabajos realizados por los becarios de la Escuela de Paisaje en La Rábida:

La temporada artística 1950-51 ha comenzado en el Salón de Exposiciones del Club La Rábida bajo los mejores auspicios, con una colectiva de pintura integrada por obras de tres pensionados de nuestra Escuela Superior de Bellas Artes, Juan Carlos Barroso y José Palomar y Armando del Río, y tres pintores procedentes de la misma y becarios de la Universidad de La Rábida, Manuel Caballero, Ricardo Comas y Joaquín Ojeda, quienes han sometido a pública sanción parte de sus trabajos realizados durante el verano en la preciada universidad.

Predominaba en la exposición el género paisajístico, en el que, dentro de cierta preocupación formal de los jóvenes artistas, había notas de positivo interés. En Barroso y Palomar los más afortunados intérpretes del paisaje empiezan a definirse características de concepto y de técnica. El primero apunta un estilo sobrio y vigoroso, en perspectivas secas de rotundos perfiles, así como en un retrato. Se nos revela además ágil dibujante en una colección de cabezas de graciosa y sencilla factura (Olmedo, 1951a, p. 158).

En el año 1951 ganó la anteriormente comentada Beca Murillo, obteniendo un premio de 10.000 pesetas (Olmedo, 1951b, p. 6). Al poco tiempo, fue galardonado con la Beca Velázquez, por su obra La Calahorra, que le sirvió para visitar y pintar las 


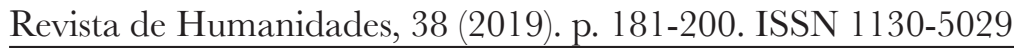

tierras de Castilla y Galicia, que ofrecieron al artista un nuevo escenario y estímulo para la creación artística (Anónimo, 1952, p. 15). A la vuelta de su periplo, expuso sus obras en la Exposición Hispano-Portuguesa de Primavera de 1952, en Sevilla, celebrada en el pabellón Mudéjar de la Plaza de América. Podríamos afirmar después de describir tan intensa actividad, que su periodo de formación fue una productiva carrera de obstáculos, donde quedaba demostrada la calidad de su pintura, ya que obtuvo prácticamente todas las becas que se concedían en aquellos tiempos.

\section{EVOLUCIÓN ESTÉTICA}

Al pintor jerezano le gustaba usar el grafito, el carboncillo, los lápices de colores, la tinta, la acuarela, el gouache... todos ellos sobre papel. A veces empleaba la acuarela y el gouache conjuntamente, obteniendo muy buenos resultados y en la mayoría de las ocasiones realizaba los apuntes con lápices de distintas calidades y colores. Conocía a la perfección la impresión en hueco-grabado sobre placa de metal con aguafuerte y punta seca. Dominaba con destreza y soltura las técnicas que aprendió en el taller litográfico familiar, pero la disciplina artística que más desarrolló durante su producción fue la del óleo. Con ella se sentía más cómodo al ser más flexible para sus exigencias, ya que le permitía tomarse el tiempo necesario para reflexionar sobre su propia manera de pintar. El óleo tenía la cualidad de soportar capas sucesivas de pigmento otorgando a las obras mayor profundidad y riqueza. “Así era cómo mi marido iba configurando su propio concepto de pintura: entre capa y capa", comentaba la viuda del artista (Dolores Fernández, comunicación personal, 17 de octubre de 2012).

Su forma de pintar cambió en los últimos años de estancia en la Escuela Superior de Bellas Artes, (tercer curso y profesorado), acentuando la geometría de sus composiciones y trabajando más que nada, el paisaje y el bodegón. Por aquel entonces sus obras mostraban un realismo tendente a lo simbólico, mezclado en muchas ocasiones, con temática religiosa, asunto que afectaba profundamente a la moral del artista y que, a su vez, le daba cierta libertad para fantasear. Según el crítico de arte del periódico $A B C$, Olmedo, el estilo pictórico de Barroso recordaba a su profesor, el pintor portuense Juan Miguel Sánchez (1900-1973), más conocido por las pinturas murales de la estación de autobuses del Prado de San Sebastián de Sevilla (Olmedo, 1952, p. 18; Banda, 2000; Fernández, 2001, pp. 257-268).

En 1952 entró mediante concurso de méritos en el Instituto Laboral de Lucena, desarrollando una gran tarea en dicho centro hasta 1956. Su labor destacó sobre todo en la docencia, así como también en la organización de conferencias, exposiciones, excursiones o en la ilustración de las numerosas revistas del centro. En esta época su estilo pictórico fue cambiando desde una representación realista de corte geométrico hacia una paulatina descomposición de la perspectiva y de las formas. 
En el año 1955 contrajo matrimonio con Dolores Fernández y al poco tiempo opositó en Madrid para optar a una plaza de profesor en la Universidad Laboral de Córdoba, recién inaugurada con el nombre de Onésimo Redondo. Consiguió el puesto y lo mantuvo hasta el año 1970 (B.O.E, 1956). La institución iba a estar regida por los Padres Dominicos y en poco tiempo Barroso sería testigo de distintos enfrentamientos entre profesores seglares, entre los que estaba él, y directivos dominicos. El pintor se sintió desencantado por la actuación de los dirigentes católicos naciendo en él un espíritu crítico hacia el catolicismo y sus administradores. No obstante, esta circunstancia no menoscabó el particular concepto de fe que mantenía el artista.

Durante esta etapa, su pintura consistió en composiciones de temática religiosa a base de superficies planas que daban lugar a una síntesis de la forma, muy cercana a los presupuestos del cubismo sintético. El artista ahondaba en su propia espiritualidad a través de la simplificación, aislando el concepto entre planos geométricos, de manera que otorgaba primacía al color, buscando lo trascendente a través del mismo. Son obras que podríamos encuadrar en una abstracción geométrico-figurativa, de tendencia expresiva [6] [7]. En algunas de estas obras, usó colores puros para crear fuertes contrastes cromáticos evocando a los pintores fauvistas [7]. A diferencia de lo que hicieron estos últimos, en la pintura de Barroso la emoción del color

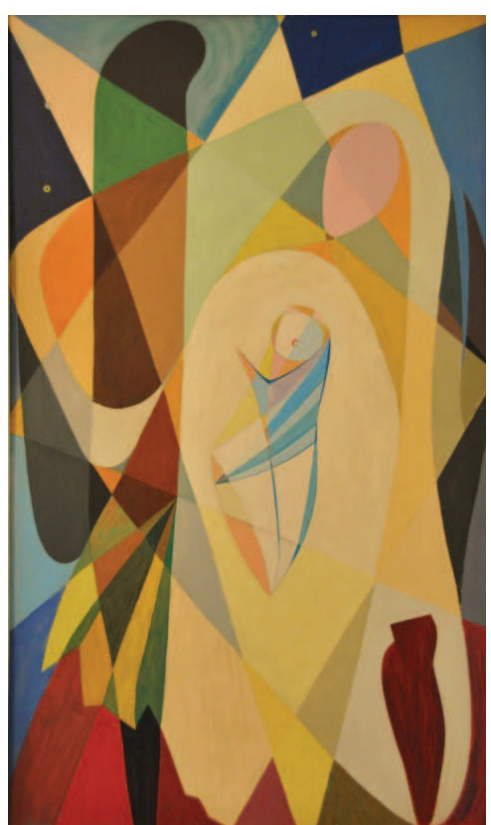

Figura 6. Juan Carlos Barroso, Ha nacido un dios, 1957. Óleo sobre lienzo, 58x98 cm, Córdoba, Colección particular

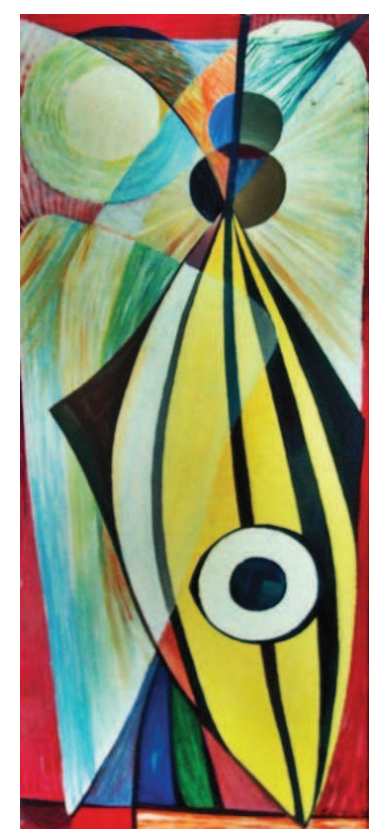

Figura 7.Juan Carlos Barroso, San Rafael, 1957. Óleo sobre lienzo, 34x84 cm, Córdoba, Colección particular 
quedaba encorsetada entre líneas cerradas. Quizás fuese la expresión callada del pintor queriendo mostrar su emoción reprimida por fuerzas más poderosas. Pues no sería la primera vez que jugaba con el lenguaje pictórico para decirnos algo que, en aquella época, no se podía decir en voz alta; recordemos el Bodegón Filosófico anteriormente estudiado.

Este modo de hacer pintura le mantuvo ocupado tres años antes de finalizar la década de los años cincuenta. Fue una fase de investigación que supuso un acercamiento al arte no imitativo, aunque nunca dejó de ser un pintor figurativo. Así afirmaba el crítico de arte Zueras, sobre su modo de pintar: "las pinturas de Barroso están dotadas de cierto sentido surrealista, de construcciones geometrizantes, restellantes de color, de buen sentido decorativo y muy personales" (Zueras, 1964).

Por estas fechas escribió numerosos artículos y conferencias, y también realizó múltiples ilustraciones para varias revistas como Spira, Aretè, Anales o Vinculo, todas ellas pertenecientes a la Universidad Laboral de Córdoba, Onésimo Redondo [8] [9].

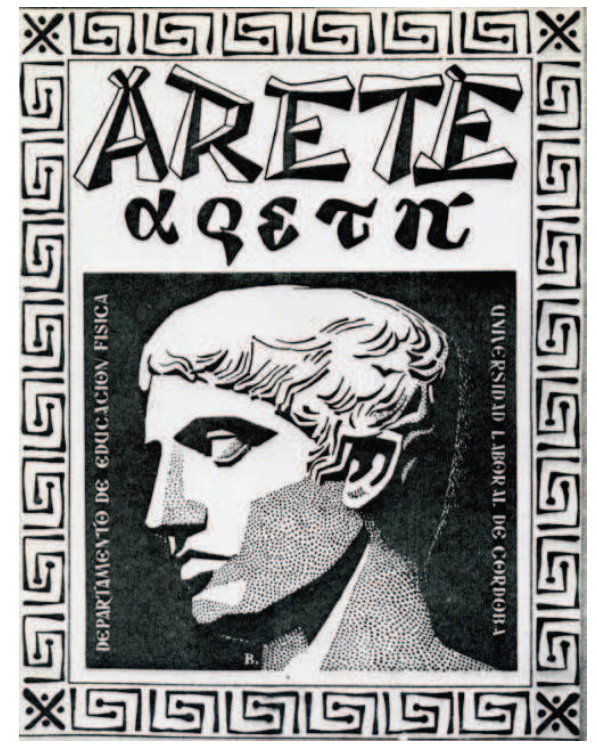

Figura 8. Juan Carlos Barroso, Diseño portada revista Areté, 1956-70. Fotograbado. Córdoba, Colección particular

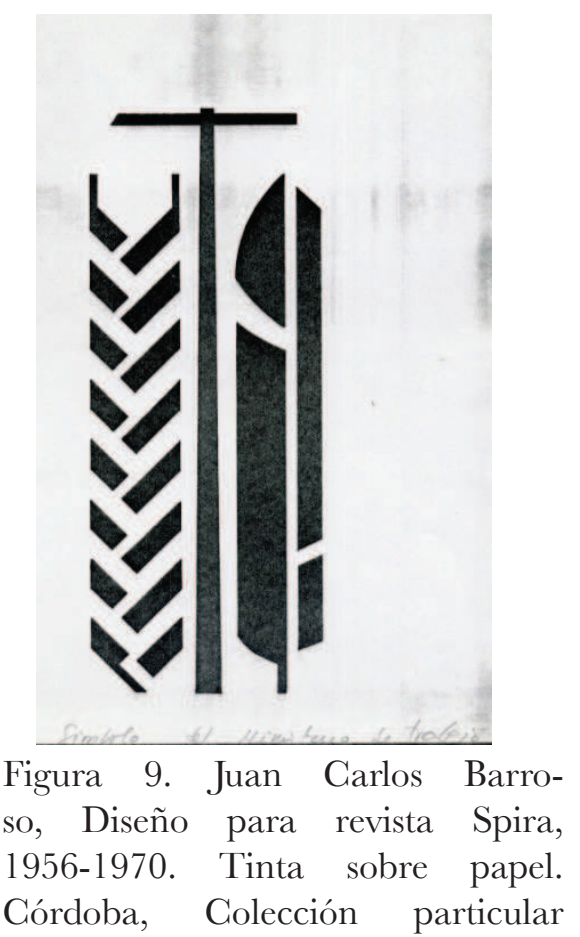

En 1960 presentó obras para la exposición colectiva Pintura Contemporánea, celebrada en la Sala Municipal del Ayuntamiento de Córdoba. En el evento participaron un gran número de artistas reconocidos por la crítica artística y otros 
que ya iban siéndolo: Picasso, Vázquez Díaz, Pancho Cossío, Largacha, Sota, Ergüín, Aguayo, Valdivieso, Liébana, Gimeno, López-Obrero, Layo, $\mathrm{M}^{\mathrm{a}}$ Manuela Pozo, Menchu Gal, Uranga, Pena, Aumenta M. Rücker, Medina, Cañete Cabbot, Mateos, Carmen Vives, Vento, Julio Antonio, John Copnall, Pedro Bueno, Del Moral, Redondela, Povedano, Carlos P de Lara, Orti M. Valdés, Martínez Novillo, García Ochoa, M. Aumente, Díaz Caneja, Trinidad Fernández, Lapayese, Palacios Tardez, Vivar, Díaz Peno, J. Valverde, Ruiz .

$\mathrm{Al}$ año siguiente participó en la fundación del Grupo Cardinal, junto con otros profesores de la Universidad Laboral. Se unieron principalmente por el ideal artístico de sus componentes y usaron la palabra Cardinal para explicar de manera simbólica el espíritu multiforme hispano, información que extraemos del Catálogo del Grupo Cardinal (1961, p. 79). Los nombres de aquellos compañeros eran Francisco Zueras Torrens (Carmona, 2006, pp. 263-326), quien llegó a ser un íntimo amigo del pintor, Felipe Criado y Antonio Ariza. Todos ellos exhibieron sus obras desde el 1 hasta el 12 de mayo en la Galería Céspedes del Círculo de la Amistad de Córdoba. Barroso presentaba: Retraso (Dña. Dolores Fernández), Simbolismo, Paisaje de Lucena, Virgen ovoide, San Rafael, Virgen, Gólgota, Ha nacido un Dios, Anunciación y Retrato de Don Luís Ortega.

Antonio Ariza presentaba: Templo de Saturno (Roma) y una talla de la Inmaculada. Zueras presentaba: Descendimiento, Aquelarre, Patio de caballos, Toros, Viajeros banderilleros, Ángel, Cristo, Amanecer, Composición, Pescadores, Payasos, El pozo (Platero y yo) y La arrulladora (Platero y yo). Y finalmente Felipe Criado presentaba: Retrato del escultor Asorey, Mercedes, Gente de Mar, Mercado (Santiago), Pesqueros (Coruña), Catedral (Segovia), San Nicolás (Córdoba), San Hipólito (Córdoba), San Pedro (Córdoba), San Agustín (Córdoba), Santa Marina (Córdoba), La Mezquita (Córdoba), y La Judería (Córdoba).

Esta muestra supuso un nuevo impulso para la joven pintura y la escultura cordobesas, que más adelante se manifestaría en exposiciones colectivas como el Salón Córdoba, celebrado en el Patio del Carmen en 1964, en homenaje al escultor cordobés Mateo Inurria.

En febrero de 1967 la universidad Laboral cordobesa, presentaba en su sala de exposiciones la muestra Corrientes pictóricas actuales a través de veinte artistas cordobeses (Zueras, 1967). En este momento se alzaban voces como la del periodista y crítico cordobés Bartolomé Mostaza, diciendo que "Córdoba gritaba la presencia europea del arte y que las últimas experiencias pictóricas y las más exigentes maestrías se daban cita en aquella muestra". Carlos Areán, otro destacado crítico de arte que trabajaba para el periódico La Vanguardia, señalaba la importancia del movimiento pictórico de la ciudad de Córdoba, considerándolo como la tercera de las escuelas de pintura españolas, después de la de Barcelona y Madrid, con "suficiente entidad y empuje" (Areán, 1972, pp. 93-96). 


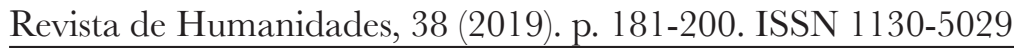

Al año siguiente, participó en la exposición Corrientes pictóricas actuales, que tuvo lugar en el Palacio de los Argensola, en Barbastro (Huesca). Concurrieron otros trece artistas, muchos de ellos reconocidos y galardonados en España y en el extranjero como José Duarte y Luís Aguilera, miembros destacados del Equipo 57 y el Grupo Espacio (Anónimo, 1968). Hay que señalar que estos artistas desarrollaron las últimas corrientes gestálticas del momento, exponiendo en París, Copenhague, Zurich, Bruselas, Zagreb o Venecia.

Desde 1961 hasta 1970, se centró en la enseñanza, trabajando con entusiasmo el dibujo técnico, asignatura obligada por su profesión que va perfeccionando en cursillos que realiza en Madrid, combinados con otros a distancia. En 1970, después de unas agotadoras oposiciones, obtuvo la cátedra de Dibujo de Institutos Nacionales de Enseñanza Media, eligiendo como destino, el Instituto de Enseñanza Media Séneca de Córdoba.

Unos años más tarde, se celebró la exposición Horizonte 74. Pintores Cordobeses (1974), en el marco de la semana cultural cordobesa, volviendo una vez más, a mostrarse la pintura local en la que Barroso participaba con obras donde la luz iba cobrando cada vez más importancia [10].

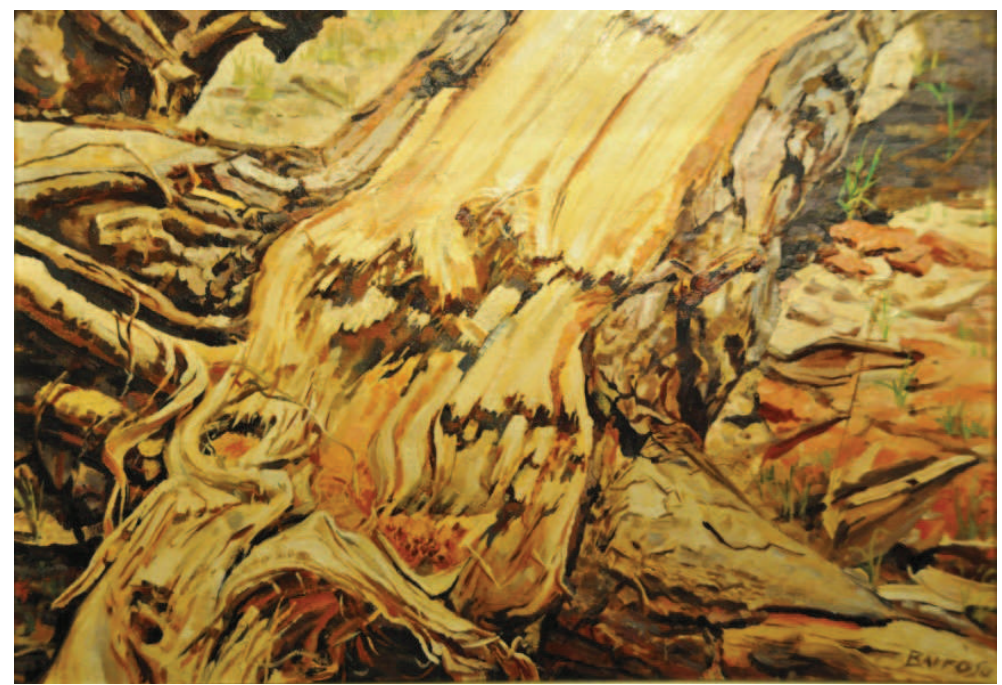

Figura 10. Juan Carlos Barroso, Árbol y salvajismo, 1978. Óleo sobre lienzo, 50x70 $\mathrm{cm}$, Córdoba, Colección particular

En ese mismo año exponía en solitario, en la galería Studio 52 (Cabello, 1974, p. 14). Muchas de sus obras pertenecían a los periodos vacacionales en los que él y su familia disfrutaban de las playas de Huelva. Fue allí donde Barroso pintaba al modo que hicieron los pintores de la Escuela de Barbizon, au plein air, trabajando 
con caballete a pleno sol en los meses de julio y agosto. La crítica sobre la clase de pintura que desarrollaba por aquellos años decía así:

Juan Carlos Barroso, debido a su sólida formación académica, posee una enorme voluntad de ejercitar la retina. Es, sin duda alguna, pintor de retina, de acción inmediata ante el modelo. Y el modelo puede ser para él unas chumberas, unas escobas o el paisaje de El Rompido, cada cosa con su luz y su peso específico. Y es pintor dominador de la luz, eso tan difícil, puesto que para captarla hace falta un fino sentido cromático, una mano apresurada que la capte al resbalar por las cosas y un espíritu moderno para no caer en el efectismo luminista (Zueras, 1979).

Barroso, hombre comprometido con su oficio, siguió combinando la docencia con el arte de la pintura, buscando tiempo para ello tanto en sus vacaciones veraniegas, como en sus momentos de descanso. Allá por los años noventa seguiría pintando pues era lo que más le gustaba, hasta que le sobrevino la muerte en el año 1995, a la temprana edad de 69 años.

\section{CONGLUSIONES}

El cambio del lenguaje pictórico que se produce en los años sesenta no se puede explicarsin un estudio pormenorizado del contexto socio-cultural de los años cincuenta. La discreta apertura política del régimen franquista significó una oportunidad única que sabrían aprovechar jóvenes artistas como Barroso para desarrollar su arte. Este pintor formó parte de los primeros artistas comprometidos con la modernidad que cambiaron el lenguaje artístico de la escena local sevillana durante la década de los años cincuenta. Su aportación artística es totalmente desconocida, al igual que la de muchos de sus compañeros de carrera, que participaron junto a él en el Grupo 49. Así pues, su labor no aparece justamente reflejada en la historiografía artística sevillana, andaluza y española. En este trabajo hemos rastreado la conexión que existió con la vanguardia de preguerra a través de dos artistas clave: Daniel Vázquez Díaz, portador de las novedades de París, y Benjamín Palencia, desde la Segunda Escuela de Vallecas. Ellos se convertirán en transmisores de las nuevas corrientes a través de la Beca de Paisaje de La Rábida y de la Primera Bienal Hispanoamericana de Arte, respectivamente. Asimismo, es esencial la presencia en la Escuela de Bellas Artes de Santa Isabel de Hungría del pintor Miguel Pérez Aguilera, cuyo magisterio rompió con el clasicismo académico imperante, introduciendo el corpus teórico asimilado en París y en la Escuela de Madrid.

En la trayectoria artística de Barroso advertimos que durante los años cincuenta su pintura va a ser más moderna y atrevida, evolucionando en los años sucesivos hacia una factura más sosegada, hasta alcanzar un intenso naturalismo. Por otro lado, es importante destacar la participación del artista en aquella oleada de pintores cordobeses considerada por la crítica, como la tercera de las escuelas de pintura españolas, después de Barcelona y Madrid. 
Revista de Humanidades, 38 (2019). p. 181-200. ISSN 1130-5029

\section{REFERENGIAS BIBLIOGRÁFICAS}

Catálogo exposición Grupo 49 (1952). Sevilla: Sevilla Gráfica.

Anónimo (8 de junio de 1952). Premios y becas de la Diputación. $A B C$, p. 15.

B.O.E. (1956), 296 de 22 de octubre, p.6724.

Catálogo exposición Grupo Cardinal (1961). Córdoba: Universidad Laboral, p. 79.

Catálogo exposición Horizonte 74. Pintores Cordobeses (1974), Córdoba.

Anónimo (6 de septiembre de 1968). Corrientes pictóricas actuales en el Palacio de los Argensola, Heraldo de Aragón.

Anónimo (25 de febrero de 2009). Escándalo por las Muchachas al sol, Diario de Sevilla.

Areán, Carlos (1972). Treinta años de arte español: (1943-1972). Madrid: Ediciones Guadarrama, pp. 93- 96.

Bonet, José Manuel (2013). Volviendo sobre la pintura de José Duarte. En catálogo exposición, Vivir desde las entrañas. José Duarte. Córdoba: Ayuntamiento de Córdoba.

Danvila, José Ramón (1990). Escenas de la vida de Pepe Duarte en Solano, F. Duarte. Córdoba: Caja Provincial de Ahorros de Córdoba.

Banda y Vargas, Antonio de la (2000). Semblanza del pintor Juan Miguel Sánchez. Revista de historia del Puerto, $\mathrm{n}^{\circ} 25$.

Burgos, Antonio (10 de marzo de 2007). El Recuadro / Adriano del Valle puso un huevo. $A B C$, p. 5.

Cabañas Bravo, Miguel (1996). Política artística del Franquismo. El hito de la Bienal Hispano-Americana de arte. Madrid: CSIC, pp. 87.

Cabello Castejón, Rafael (11 de abril de 1974), Barroso, en Galería Studio de Córdoba, $A B C$, p. 14.

Carmona Carmona, Francisco Manuel (2006). Francisco Zueras Torrens. Argensola: Revista de Ciencias Sociales del Instituto de Estudios Altoaragoneses, $n^{\circ} 116$, pp. 263-326.

D'Agosto Forteza, Sonia (2014). La Escuela de Estudios Hispanoamericanos y su papel dinamizador en la ciudad de Sevilla. Arte y Ciudad, pp. 43-45.

D’Agosto Forteza, Sonia (2016), Antonio Rodríguez de Trujillo (1925-1989) y la metamorfosis de su pintura. Ars Longa.

D’Agosto Forteza, Sonia (2017), José Duarte, el artista valiente. Grupo de Investigación Arte, Arquitectura y Comunicación en la Ciudad Contemporánea.

Esteban Drake, Mesa (1991). De El Paular a Segovia.1919-1991. Segovia: Diputación Provincial, p. 167.

Faraldo, Ramón (1953). Espectáculo de la pintura española. Madrid: Cigüeña.

Fernández Cabaleiro, María Begoña (2015). La Escuela de Madrid en la crítica de arte del Franquismo: La «nunca rota» conexión con la Vanguardia. Espacio, tiempo y forma, pp. 101-102. 
Juan Carlos Barroso (1925-1995): un testimonio... - S. D’ Agosto Forteza

Fernández Rojas, Matilde (2001). Las pinturas murales de Juan Miguel Sánchez Fernández en la estación de autobuses del Prado de San Sebastián de Sevilla. Archivo Hispalense, ${ }^{\circ}$ 256-257, pp. 257-268.

Gauthier, Marina (2006). Expressionisme et Realisme onirique en Espagne: L'Oeuvre de José Duarte (1928). Tesis doctoral inédita. Universite de Toulouse-Le Mirail.

Gómez Bravo, Gutmaro (2009). El exilio interior. Cárcel y represión en la España franquista (1939-1950). Madrid: Editorial Taurus, p. 117.

Hispaleto, Juan (17 de abril de 1952). Otra Exposición Juvenil: la del Grupo 49. Sevilla, p. 6.

Martín Martín, Fernando (1992). Notas sobre la creación contemporánea en Sevilla. En catálogo exposición, Pintores de Sevilla 1952-1992. Sevilla: El Monte.

Martínez Cerezo, Antonio (1977). La Escuela de Madrid. Madrid: Ibérico Europea, p. 37.

Merino Calvo, José Antonio (1987). Tradición y contemporaneidad: el escultor Juan Luis Vassallo Parodi. Cádiz: Fundación Municipal de Cultura.

Olmedo, Manuel (enero de 1951a). Exposición colectiva, Revista Estudios Americanos, $\mathrm{n}^{\circ} 8$, p. 158 .

Olmedo, Manuel (16 de agosto de 1951b). Los premios de pintura de la Diputación Provincial. $A B C$, p. 6 .

Olmedo, Manuel (18 de abril de 1952). Exposición del Grupo 49. ABC, p. 18.

Pérez Gamero, David (2008). La escultura sevillana en tiempos del nacional-catolicismo. En Giménez de Aragón, Pedro, Escultores sevillanos del siglo XX. Sevilla: Caja Rural del Sur, p.143.

Picasso, Pablo et al. (1 de noviembre de 1951). Este es el manifiesto de Picasso. Propone una contrabienal... en París. Correo Literario, nos. 34-35, pp. 1 y 8.

Revilla, Federico (1990). Diccionario de iconografía. Madrid: Cátedra.

Sánchez Camargo, Manuel (1954). Pintura española contemporánea. La nueva Escuela de Madrid. Madrid: Cultura Hispánica.

Sánchez Camargo, Manuel (1963). Historia de la Academia Breve de Crítica de Arte. Homenaje a Eugenio d'Ors. Madrid, p., 22.

Sánchez González, Irene (2009). Historia del Ateneo de Sevilla. Sevilla: Colegio Oficial de Aparejadores y Arquitectos Técnicos de Sevilla, p. 128.

Tamamés, Ramón (1989). La República. La Era de Franco. Madrid: Alianza, pp. 423-424.

Torres Martín, Ramón (24 de octubre de 1976). El Grupo 49 y la Joven Escuela Sevillana. Correo de Andalucía, p. 30.

Zueras, Francisco (8 de julio de 1964). La Nueva Figuración y el Informalismo en el Salón de Córdoba. Informaciones.

Zueras, Francisco (1967). Corrientes pictóricas actuales a través de veinte artistas cordobeses. Universidad Laboral.

Zueras, Francisco (1979). Juan Carlos Barroso. Galería de arte Manuela. 